\title{
Creating Environmental Awareness using an Eco-Feedback Application at a Higher Education Institution
}

Andre Calitz, Margaret Cullen and Francois Odendaal, Nelson Mandela University, South Africa

\begin{abstract}
Providing environmental education and creating environmental awareness assists future generations to conserve, preserve and sustain the environment. Organisations are supporting environmental awareness education efforts and universities are increasingly being required to exercise sound environmental behaviour and educate all stakeholders on their responsibility of being aware of their environmental impact. Gamification and eco-feedback applications in previous studies have been used to provide feedback on an individual's behaviour with the goal of creating environmental awareness. Students are generally not provided with environmental information regarding their use of electricity, water and waste management whilst on campus. In this exploratory study, an eco-feedback application was developed and used to create environmental awareness amongst postgraduate students at the Nelson Mandela University and the functionality of the eco-feedback application was evaluated. The results indicated that participants became more aware of their environmental impact after being exposed to an eco-feedback application. The functionality provided by the eco-feedback application, to assist in creating environmental awareness within an academic institution, proved to be useful.
\end{abstract}

Keywords: environmental awareness, eco-feedback applications, behavioural change theory

\section{Introduction}

Globally, organisations are promoting environmental awareness and responsibility (Kencanasari, Surahman \& Permana, 2019). Increased environmental awareness allows organisations to implement better sustainable practices and improve their competitive advantage (Walton \& Galea, 2005). Universities are increasingly being required to exercise sound environmental behaviour and educate all stakeholders on their responsibility of being aware of their environmental impact (Kaur, 2019).

The recording and reporting of environmental data, such as electricity and water usage and waste management information, in an organisation can assist with reducing the overall environmental impact (Jakobi \& Schwartz, 2012). If organisations manage their environmental data, by adopting new technological applications that will allow information 
sharing, such as the sharing of electricity usage information, they will be able to reduce energy consumption (Jain, Taylor \& Peschiera, 2012). Information regarding electricity and water usage can be used by individuals and organisations for better decision making and to create environmental awareness (Hough, Thompson, Strickland \& Gamble, 2011; Kencanasari, et al., 2019). Individuals who are aware of their environment-impacting activities can act to decrease their electricity and water consumption, leading towards sustainable development practices (Olsen, 2014).

Creating environmental awareness is critical and has resulted in an increase in the development of applications to support individuals monitoring their environmental impact (Gadenne, Kennedy \& McKeiver, 2008; Jorgenson, Stephens \& White, 2019). Modern technologies are gradually being adopted to communicate environmental alerts, awareness and concerns and promote eco-friendly behaviour (Piccolo et al., 2012; Hamid et al., 2018).

Modern technologies are used to help raise environmental awareness and motivate ecofriendly behaviour to nurture environmentally aware individuals and students (Castelli et al., 2017; Dubois \& Pittarello, 2018). Several gaming applications, including serious games and eco-feedback applications have been used for environmental management education at Higher Education Institutions (HEIs) (Madani, Pierce \& Mirchi, 2017). These applications provide feedback on individual and group behaviour with the goal of reducing environmental impact (Jakobi \& Schwartz, 2012; Jain et al., 2012).

This paper investigates the use of an eco-feedback application implemented the Nelson Mandela University (NMU) to determine the effect of the use of the eco-feedback application on the environmental awareness of postgraduate students. This paper includes a literature review (Section 2), which provides a discussion on environment education and awareness, gamification and eco-feedback technologies. A theoretical perspective is also provided. The development of the eco-awareness application is explained in Section 3 and the research methodology is presented in Section 4. Section 5 highlights the results from the comparison between the pre-test and post-test used for the evaluation of the use of the eco-feedback application. The paper concludes with a discussion on the contribution of the research and recommendations for future work (Section 6).

\section{Literature review}

\section{Institutional environmental impact}

HEIs produce large amounts of greenhouse gas emissions through electricity (Association for the Advancement of Sustainability in Higher Education, 2012). Limiting the use of electricity and water, together with recycling efforts, in promoting sustainable development, has a positive impact on the environment. HEIs should strive to reduce electricity and water consumption as well as promote recycling activities to reduce their environmental impact. The energy use of these institutions needs to be closely monitored and recorded (KleinBanai \& Theis, 2013). The visualisation of electricity and water usage within buildings can create awareness and help decrease the impact on the environment (Cetin \& Nisanci, 2010). 
The use of modern technologies can create environmental awareness and influence the behaviour of staff and students (Dubois \& Pittarello, 2018). Social media platforms (such as Facebook and Twitter) have also been used effectively to create environmental awareness amongst staff and students in higher education (Hamid et al., 2018).

The promotion of pro-environmental behaviour and the understanding of individual actions in areas of water and electricity consumption, recycling and waste management, can reduce the impact individuals have on the environment (Kollmuss \& Agyeman, 2002). The insights gained from pro-environmental behaviour studies have been applied in a study relating to university students by Thondhlana and Hlatshwayo (2018) who highlighted the need to encourage environmental behaviour in university residence settings and promote pro-environmental actions.

\section{Environmental education and awareness}

Environmental education aims to increase an individual's environmental awareness (Cruz \& Tantengco, 2017; Jakobi \& Schwartz, 2012; Jain et al., 2012). Environmental education allows individuals to explore environmental issues, engage in problem solving and participate in actions to restore and protect the environment. As a result, individuals develop a deeper understanding of environmental issues and have the skills to make informed and responsible decisions. If individuals are aware of the negative consequences of their daily activities and how these activities have an impact on the environment, they would be more concerned about their environmental impact (Olsen, 2014).

Environmental awareness research indicates that HEIs are increasingly becoming aware of promoting environmental awareness amongst students (Kaur, 2019). In a study on environmental awareness among college students in India, the researchers found that environmental awareness differs with socio economic status for students and that no difference was observed between males and females (Kaur, 2019). Sulaiman, Chan and Ong (2019) evaluated factors that influence recycling intentions among university students and found that past behaviour had a strong impact on recycling intention amongst students.

Instruments and technologies have been developed for measuring environmental awareness (Hartman et al., 2018). Environmental awareness includes factors such as knowledge, attitudes and behaviour or actions (Kencanasari et al., 2019). Biographical variables identified in environmental education studies included race, ethnicity, gender, socio-economic and religion (Derr, 2020).

\section{Gamification and serious games}

Human behaviour plays an important role in energy usage, water consumption and waste management; however, efforts to target behavioural change have produced varying levels of success (Johnson et al., 2017). Energy and water consumption and waste management are significant, critical, social and environmental issues. Gamification and serious games offer a means of influencing people (and specifically students) regarding these important issues (Hamari, Koivisto \& Sarsa, 2014). 
Gamification can be defined as the use of game elements in a non-game context to improve the user experience and user engagement. Serious games are defined as any form of interactive computer-based or mobile-based game software for one or multiple players to use with the intention of being more than entertainment. The distinction between gamification and serious games is that serious games are fully fledged games (e.g., a digital role-playing game in which the player completes challenges or quests designed to educate them about environmental factors, such as energy consumption), while gamification refers to the application of parts of games in a non-game setting (e.g., a mobile app designed to track and encourage actions, that uses different avatars, levels, rewards and badges) (Johnson et al., 2017).

Johnson et al. (2017) evaluated 25 gaming studies and grouped them into four categories, namely behavioural outcomes, cognitive outcomes, learning and knowledge acquisition outcomes and user experience. Behavioural outcomes are specifically applicable in environmental behaviour studies and included both actual and intended behaviour outside the game or application (referred to as real world behaviours). Real world behavioural outcomes included energy consumption, energy saving activities/actions and intention to engage in energy-saving behaviour.

Serious games have been used for environmental management education in higher education (Madani et al., 2017). Research has shown that playing a serious game affects people's attitudes towards the environment and the sustainability of their behaviour (Chappin, Bijvoet \& Oei, 2017). Additionally, games have been used for the teaching and awareness of environmental issues and problems. Souza et al.(2019) developed and evaluated a serious game to raise environmental awareness and prevention of water pollution. They found that the game affected players' knowledge about environmental issues and that in a pre-test post-test scenario, the participants were slightly more aware of how different types of waste affected the environment.

\section{Eco-feedback technologies}

Eco-feedback technologies provide environmental usage information to individuals and/ or organisations to promote awareness of their impact and encourage behavioural change to minimise this usage (Froehlich, Findlater \& Landay, 2010). A key feature of an ecofeedback application is to have a clear goal based on historical data, providing feedback and associated required action(s) using tips and hints (Fitzpatrick \& Smith, 2009; Spagnolli et al., 2011). Such applications should be unobtrusive, display simple, easily understandable information and use intuitive and logical metaphorical indicators to simplify feedback (Spagnolli et al., 2011).

Eco-feedback technologies therefore do not only have the ability to create awareness of environmental impact, but also influence the user on a physiological and behavioural level (Yendapally \& Yazdansepas, 2020). Spagnolli et al. (2011) also proposed that eco-feedback technologies make use of intuitive and logical metaphorical indicators to simplify feedback. This not only requires less thinking from the users' side but may also give a more visual 
and often more effective expression of feedback. As an example, Fitzpatrick and Smith (2009) suggest the use of traffic light colours, i.e. red, orange and green, to indicate the severity of environmental impact levels. Such use of metaphors provides an effective, visual comparison of usage to target usage and should change in response to improvements or declinations of these comparisons.

The integration of eco-feedback technologies with smart phone applications, using 3D interfaces on university campuses, promotes emotional engagement and cognitive involvement (Dubois \& Pittarello, 2018). The feedback provided by serious games, such as badges and rewards, could further be integrated with eco-feedback technologies to positively impact on the personal environmental behaviour of students.

\section{Theoretical perspective}

Presently, researchers apply different theoretical perspectives to create environmental awareness (Akintunde, 2017). Akintunde (2017) suggested an integrative application of different behavioural and environmental theories to help solve contemporary environmental problems. The expected outcome of this study was to increase the environmental awareness of students through the use of an eco-feedback application. It is therefore important to refer to behavioural models and related theories. The behavioural change model proposes that if people are better informed, they would become more aware of environmental issues and behave in an environmentally responsible manner (Prochaska, Johnson \& Lee, 1998). The theory of environmentally responsible behaviour (Hines, Hungerford \& Tomera, 1987) argues that, amongst others, attitudes and knowledge through education, suggest whether a person would adopt a behaviour or not.

The behavioural change model indicates that when knowledge increases, environmentally favourable attitudes develop responsible environmental actions (Akintude, 2017). The behavioural model provides a base for the consideration of possible relationships existing between environmental knowledge, environmental awareness and attitude and how these factors can lead to action. Shove, Pantzar and Watson (2012) criticised the narrow use of behavioural change theories in the field of environmental change for focusing too much on the individual's behaviour and mentioned that the view should be broadened to include social interaction, lifestyles, norms and values as well as technologies and policies as enablers or hindrances for behavioural change. This exploratory study includes all these factors with the exception of policy. The results of this study can provide a foundation for future studies that could inform environmental policy development for a university.

The feedback intervention theory proposes that feedback is an important component of many educational programmes and interventions. Feedback refers to the process of giving people information about their behaviour that can be used to reinforce and/or modify future actions (Karlin, Zinger \& Ford, 2015). Bandura (1969), in his work on feedback, found that providing a goal and information about progress toward that goal could serve as a form of behaviour modification, much like providing a reward or punishment. Feedback after consumption can be either "direct" or "indirect" (Darby, 2006). Direct or real-time 
feedback, which is more effective, is immediate and from a meter, other display monitor or application. Direct feedback can lead to behavioural change (Van Houwelingen \& Van Raaij, 1989; Vine et al., 2013).

\section{The eco-feedback application}

Monroe et al. (2019) summarised various literature studies and the methods and interventions used to identify and create effective environmental and climate change education strategies. These strategies aimed to improve environmental knowledge, change attitudes, empower action and change behaviour. Fraternali et al. (2019) presented insights drawn from recent research projects aimed at developing visualisation and gamification tools to stimulate individual behaviour to change and promote energy and water savings. Studies used tools such as pre/post-test and specifically validated surveys, such as the 2MEV scale to measure environmental attitudes (Monroe et al., 2019).

NMU students and staff had no direct means of viewing their environmental consumption and therefore were unaware of the institution's environmental impact. Students have daily access to personal computers on campus, which provided an appropriate and effective means to deliver campus related environmental information, using an eco-feedback application. The design of eco-feedback applications to improve environmental awareness and provide timely feedback have had a positive impact on creating increased environmental awareness (Dubois \& Pittarello, 2018). This study created the first eco-feedback solution for the NMU and its usefulness for creating environmental awareness was evaluated.

A number of existing eco-feedback tools and mobile applications were evaluated before designing the user interfaces for the NMU Eco-Feedback application (Yendapally \& Yazdansepas, 2020; Dubois \& Pittarello, 2018). Existing literature focusing on the design of eco-feedback applications for improving environmental awareness on a university campus were reviewed (Dubois \& Pittarello, 2018) and several prototypes were developed using an iterative approach. The aim of the study was to develop an application to assist students to become aware of their impact on the environment and to motivate them to change their environmental behaviour. The usability of the NMU Eco-Feedback application was evaluated by staff and postgraduate students from the Department of Computing Sciences at NMU.

The NMU Eco-Feedback application used data directly from NMU's environmental information database. The environmental information database stores weekly and monthly electricity usage, water consumption and waste data for each building on campus and was used for data acquisition for this study (Calitz \& Zietsman, 2018). The NMU Eco-Feedback application was developed as a Windows' application (Figure 1), which was run when the students logged onto the NMU network. The information displayed included water and electricity usage, as well as waste management data of NMU, how well these levels compare to predetermined targeted levels, specific buildings' electricity, water and waste recycling data, a summary of all levels of usage at NMU and tips on how to reduce water and electricity 
usage and increase recycling (Figure 3). The application further provided more in-depth drill-down information, including historical data.

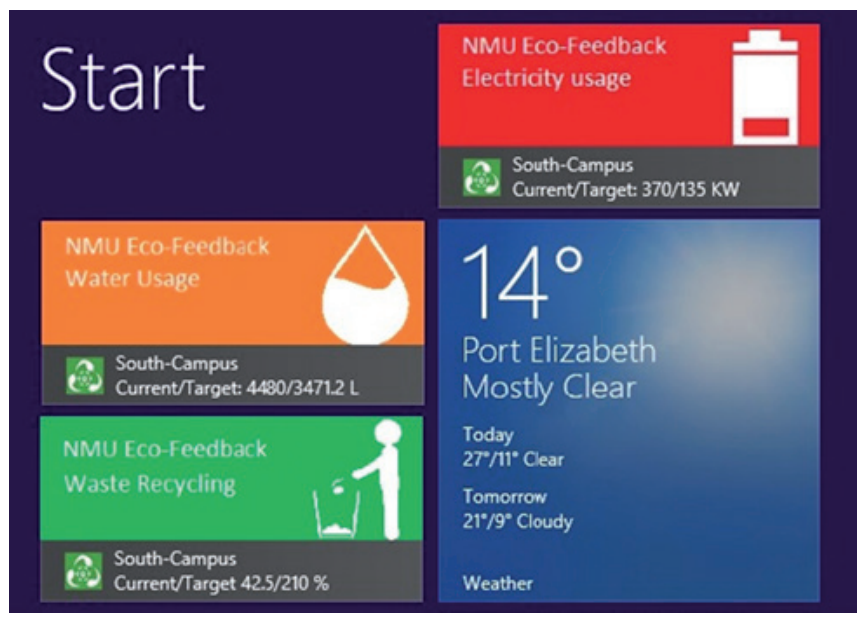

Figure 1: An example of the live tiles of the Eco-Feedback application on the Windows start screen

Colour-coding was used to indicate how the current environmental resource usage related to the targeted usage levels, namely green indicating good, orange indicating moderate and red indicating poor as suggested by Fitzpatrick and Smith (2009). Different icons were also used to represent electricity, water and waste levels (Figure 2). Additionally, customisation of the user interface was supported to allow the user to filter the information displayed and activate or de-activate certain features. The user of the application could select buildings and obtain environmental data on electricity usage and water consumption (Figure 2), including waste management for a specific building, residence or campus.

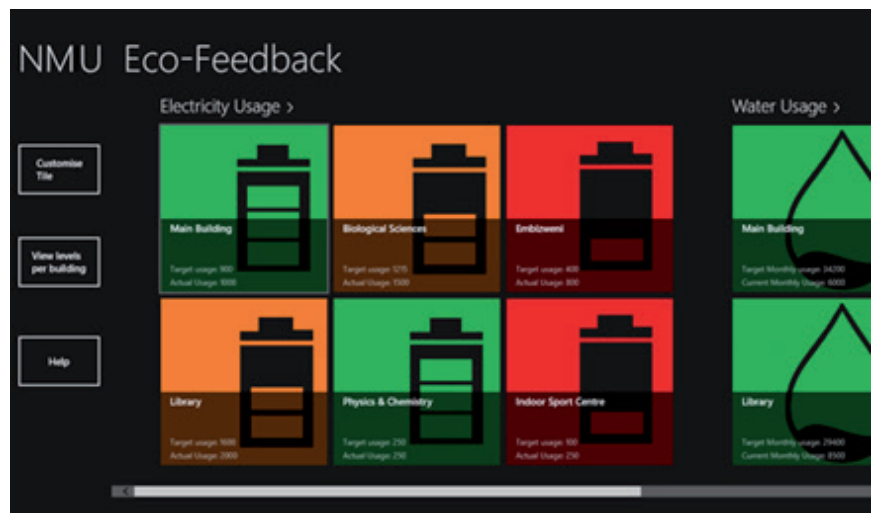

Figure 2: The user interface of the main Eco-Feedback application 
The Eco-Feedback application further provided daily environmental tips to students (Figure 3).
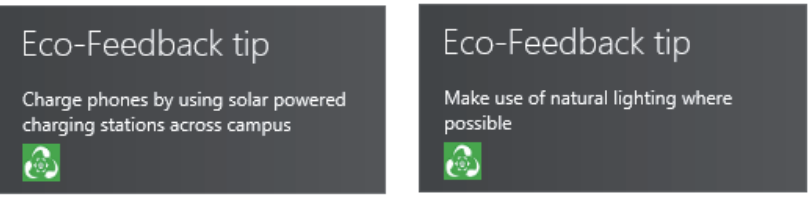

Figure 3: Eco-Feedback application environmental tips

\section{Research methodology}

The research problem addressed in this exploratory study was that postgraduate students were not aware of their environmental impact whilst on campus. The research objective of this exploratory study was to develop an eco-feedback application that could be used to create environmental awareness of electricity and water consumption levels in order to reduce its overall environmental impact. The research question of the study was: To what extent could the use of an eco-feedback application raise students' awareness of their environmental impacts on campus?

The research approach applied in this study was a literature synthesis followed by an experimental assessment of an artifact, namely the NMU Eco-Feedback application. A convenience sample of sixteen participants, the Computer Science Honours class, participated in the study. The students completed a pre-test questionnaire, prior to using the eco-feedback application and a post-test questionnaire, after four weeks using the application. The questionnaire evaluated student's awareness of environmentally friendly behaviour on campus. In accordance with similar research relating to creating environmental awareness and the evaluation thereof (Zyadin, 2015; Biswas \& Roy, 2016; Cruz \& Tantengco, 2017), quantitative feedback was captured using the pre- and postquestionnaires. The usefulness of the eco-feedback application was also evaluated. Ethics approval was obtained from the NMU Ethics Committee for the study.

\section{Evaluation method and tasks}

The students were provided with a pre- and post-test questionnaire (Figure 4) using a 5 -point Likert scale ( 1 = Strongly disagree to $5=$ Strongly agree). The statements focused on knowledge, attitudes and behaviour (Kencanasari et al., 2019). The 16 students completed the questionnaire before the four-week environmental awareness intervention and again after the intervention, in order to determine the effect of using the NMU eco-feedback application.

The environmental data for the university was displayed (Figure 1) during the four weeks of the experiment when the 16 students logged onto the NMU computer network. 
The participants were required to find relevant information regarding buildings' electricity and water usage and waste management. They viewed a daily environmental tip (Figure 3) and had to complete various tasks including:

- Customising the eco-feedback application;

- Recording a specific building's electricity and water usage reading for a certain month and year;

- Determining which buildings on campus where performing the poorest;

- Viewing how well these levels compared to predetermined targeted levels;

- Viewing a summary of all data on a specific campus.

\section{Results}

The biographical data of the 16 postgraduate participants from the NMU Department of Computing Sciences indicated that the age of the students ranged between 21-24 years. Seven participants were females and nine were males. Six students lived in a university residence and ten lived in off-campus accommodation. All students had at least four years of experience in Microsoft Windows.

The results from the eight questions relating to environmental impact, answered by students before using the NMU Eco-Feedback application and four weeks later, after using the application, are presented in Figure 4. Figure 5 indicates the average percentage change per question.

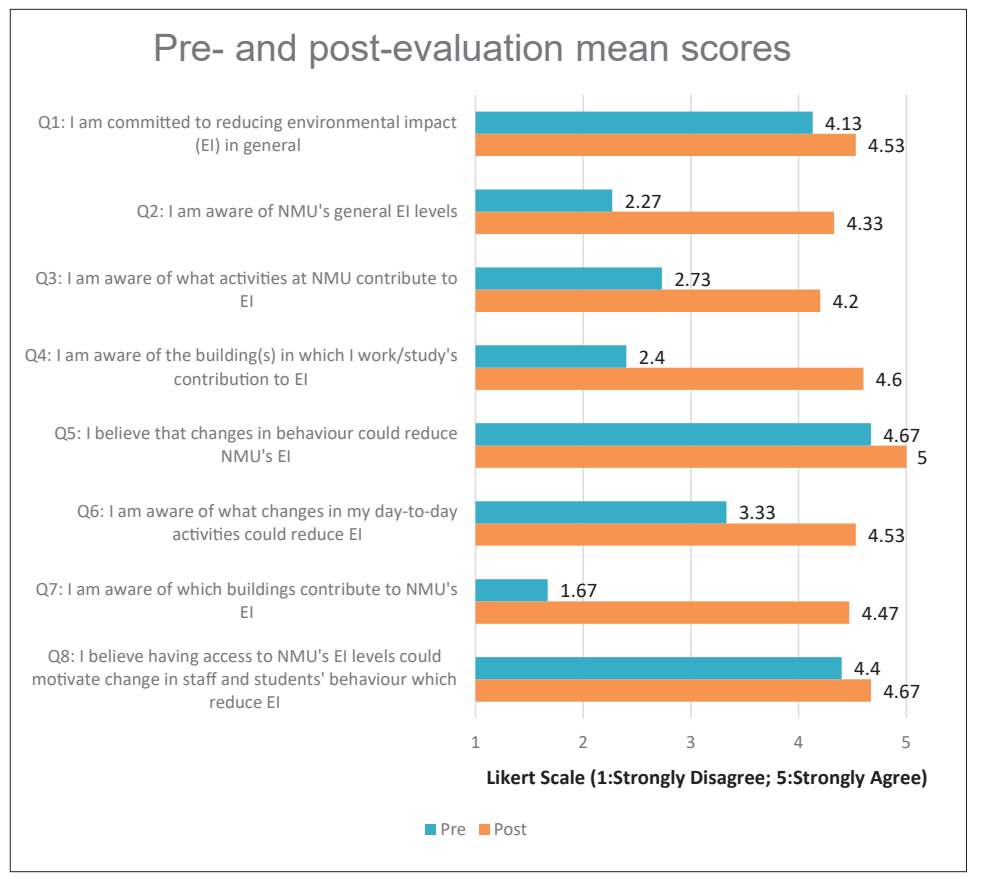

Figure 4: Pre-and post-test evaluation mean scores for environmental impact statements 


\section{Average percentage change per question}

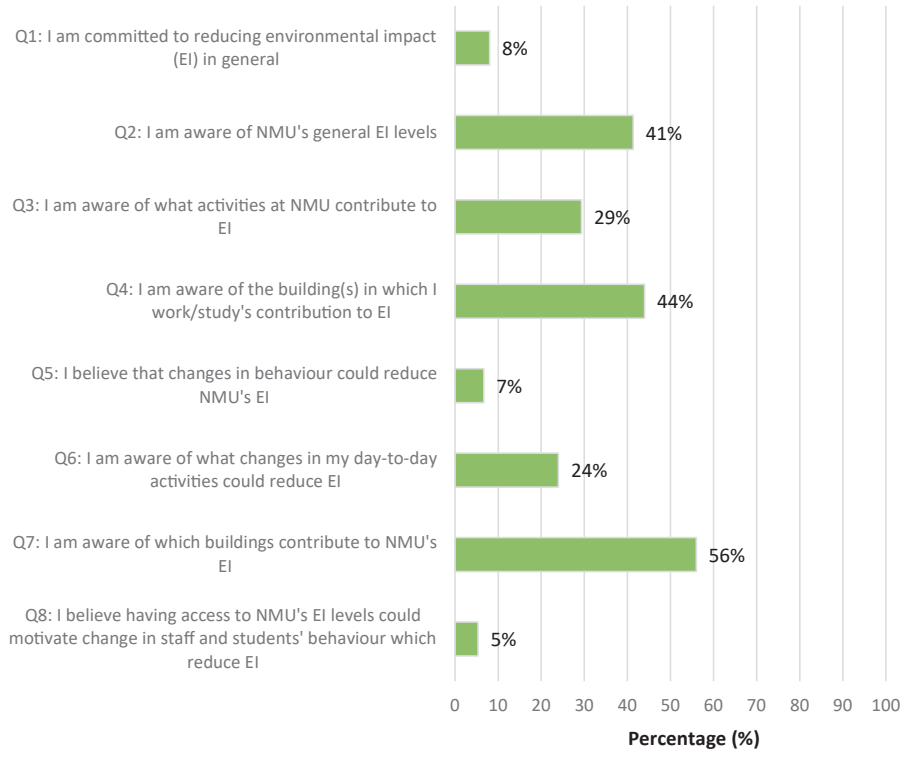

Figure 5: Average percentage change perquestion

Table 1 indicates the increase in environmental impact awareness created by the functionality provided by the NMU Eco-Feedback application.

Table 1: Awareness questions linked to system functions

\begin{tabular}{|c|c|c|c|}
\hline Question & Create awareness of... & System function & $\%$ increase \\
\hline 2 & impact levels & $\begin{array}{l}\text { Display environmental impact levels and } \\
\text { comparisons }\end{array}$ & $41 \%$ \\
\hline 3 & $\begin{array}{l}\text { activities which contribute to } \\
\text { environmental awareness }\end{array}$ & $\begin{array}{l}\text { Display and categorise electricity, water and } \\
\text { recycling waste levels }\end{array}$ & $29 \%$ \\
\hline 4 & $\begin{array}{l}\text { environmental impact of } \\
\text { building in which participant } \\
\text { operate }\end{array}$ & $\begin{array}{l}\text { Display impact levels of each building, } \\
\text { customise live tiles to display data of specific } \\
\text { building }\end{array}$ & $44 \%$ \\
\hline 6 & $\begin{array}{l}\text { what changes in activities } \\
\text { can reduce impact }\end{array}$ & $\begin{array}{l}\text { Provide tips on how to reduce impact, } \\
\text { customise Live Tile to display tips }\end{array}$ & $24 \%$ \\
\hline 7 & $\begin{array}{l}\text { which specific buildings } \\
\text { contribute to impact to what } \\
\text { extent }\end{array}$ & $\begin{array}{l}\text { Compare impact levels across buildings and } \\
\text { other impact levels }\end{array}$ & $56 \%$ \\
\hline
\end{tabular}


Table 2 presents the results from the one-sample t-tests relating to the eight questions, including the practical significance as indicated by Cohen's $d$. Cohen's $d$ is an appropriate effect size for the comparison between two means and a Cohen's $d$ value greater than 0.8 indicates a large effect size.

Table 2: One-sample t-tests: Q1 to Q8 ( $n=16 ; H 1: \mu \neq 0.00 ;$ d.f. $=23)$

\begin{tabular}{|c|c|c|c|c|c|c|}
\hline Items & Mean & S.D. & $\mathbf{t}$ & $\mathbf{p}$ & Cohen's d & Practical \\
\hline Q1 & 0.71 & 0.81 & 4.30 & $<.0005$ & 0.88 & Large \\
\hline Q2 & 2.13 & 1.23 & 8.48 & $<.0005$ & 1.73 & Large \\
\hline Q3 & 1.71 & 1.16 & 7.21 & $<.0005$ & 1.47 & Large \\
\hline Q4 & 2.29 & 1.37 & 8.21 & $<.0005$ & 1.68 & Large \\
\hline Q5 & 0.96 & 1.08 & 4.34 & $<.0005$ & 0.89 & Large \\
\hline Q6 & 1.63 & 0.97 & 8.21 & $<.0005$ & 1.68 & Large \\
\hline Q7 & 2.83 & 0.96 & 14.41 & $<.0005$ & 2.94 & Large \\
\hline Q8 & 0.63 & 0.82 & 3.71 & .001 & 0.76 & Large \\
\hline
\end{tabular}

\section{Discussion}

Eco-feedback technologies aim to make people aware of their impact on the environment in order to motivate action that reduces this level of impact (Dubois \& Pittarello, 2018). The evaluation of the use of the NMU Eco-Feedback application by the students involved a comparison of the responses to the eight items, labelled Q1 to Q8 (Figure 4). The survey was conducted between the pre-test, completed by participants prior to using the NMU EcoFeedback application and the same eight items in the post-test questionnaire, completed four weeks after using the application. The aim of this comparison was to determine whether the NMU Eco-Feedback application had a positive impact on the participants' environmental awareness.

\section{Pre- and post-test research findings}

All students recorded a higher post-test score compared to the pre-test ratings (Figure 4). Participants perceived themselves to be more committed to reducing their general environmental impact after using the NMU Eco-Feedback application (Q1: $\mu=4.53)$. Participants felt strongly that changes in behaviour can reduce the university's environmental impact (Q5: $\mu=5$ ) and thus having access to the university's environmental data can motivate a change in their behaviour (Q8: $\mu=4.67$ ). 
The students emphasised the need for an eco-feedback application at NMU, after using the NMU Eco-Feedback application, as these statements received higher ratings in the post-test. All items related to the awareness of NMU's environmental impact were rated higher after the use of the NMU Eco-Feedback application (Q2: $\mu=4.33$; Q3: $\mu=4.2 ; \mathrm{Q} 4$ : $\mu=4.6$; Q7: $\mu=4.47$ ). The use of the application assisted in allowing participants to be more aware of changes they could make in their daily activities to reduce their environmental impact (Q6: $\mu=4.53)$.

The average percentage change per statement (Figure 5) illustrates which items were rated higher in the pre- and post-tests. Participants became more aware of NMU's environmental impact using the NMU Eco-Feedback application, as can be seen by the positive changes in items Q2 (41\%), Q3 (29\%), Q4 (44\%) and Q7 (56\%). The application also assisted in helping participants become more aware of what changes can be made in their daily activities to reduce their environmental impact (Q6: 24\%).

The remaining statements had smaller positive change between pre- and post-tests. Participants indicated that they were more committed to reducing their environmental impact after using the NMU Eco-Feedback application (Q1: 8\%), they believed that changes in behaviour can reduce NMU's environmental impact (Q5: 7\%) and that providing access to such information provided by the NMU Eco-Feedback application could assist in changing a student's environmental awareness (Q8: 5\%). It appears then that the use of an eco-feedback application at an academic institution could encourage positive environmental behavioural change within the institution, as well as in the students' daily lives. The students further indicated that the NMU Eco-Feedback application provided useful feedback with regard to the environmental data at NMU.

\section{One sample t-tests for the pre- and post-tests}

In order to determine the significant effect from the sample, t-tests and Cohen's d calculation were performed. Cohen's d is used to represent the extent of differences between two (or more) groups of a given factor (Salkind, 2010). Cohen's d is used for practical significance in a one-sample t-test. The interpretation intervals for practical significance indicated by a Cohen's d value are Not significant (<0.20), Small (0.20-0.49), Medium (0.50-0.79) and Large $(0.80+)$ (Gravetter \& Wallnau, 2009). Caution must, however, be taken when interpreting Cohen's d values for small sample sizes.

A one-sample t-test of the factors with the sample size of 16 , was performed to determine the existence of statistical and practical significance (Table 2). A p-value of less than 0.5 indicates statistical significance, while Cohen's d value indicates practical significance. Table 2 indicates that all the items had a positive mean score and a large practical significance, as indicated by Cohen's d. The comparison between the pre- and post-tests confirmed that the NMU Eco-Feedback application supports the purpose of an eco-feedback application, as indicated by Dubois and Pittarello (2018). The application provided useful environmental information to promote awareness of the institution's environmental impact. The students became more aware of water and electricity consumption on campus. 


\section{Conclusions and future research}

The design and use of eco-feedback systems for improving environmental awareness of people on a university campus leads to an increase in environmentally aware lifestyles (Dubois \& Pittarello, 2018). The use of eco-feedback technologies provides users with feedback on the impact of their actions towards the environment (Yendapally \& Yazdansepas, 2020). Ecofeedback technologies have further been used to create environmental awareness (Spagnolli et al., 2011; Fraternali et al., 2019). Johnson et al. (2017) reported that applied games can have a positive effect on energy related domains and can potentially influence behaviour or behavioural antecedents.

The process followed in this study, establishing environmental awareness levels, introducing an eco-feedback application as an educational tool and the re-evaluation of awareness levels, supports the behavioural change theory. According to Kencanasari et al. (2019), the environmental awareness indicators include factors such as knowledge, attitudes and behaviour or actions. However, Shove et al. (2012) believe that this is too narrow and should be broadened to include social interaction, lifestyles, norms and values as well as technologies and policies in addition to individual behaviour. This study was approached from the broader view and included a high percentage of these factors.

In this exploratory study, the use of and exposure to an eco-feedback application, made participants more aware of the electricity, water and waste impacts at the university. The feedback intervention theory advocates that feedback is an integral component of many educational programmes (Karlin et al., 2015). The NMU Eco-Feedback application provided real-time feedback, which supports the feedback intervention theory. Dubois and Pittarello's (2018) findings also indicated that eco-feedback interfaces required cognitive involvement and emotional engagement by users on a university campus. Overall, the results of the comparison between the pre- and post-tests indicated that the NMU EcoFeedback application provided support in creating environmental awareness. Participants were generally much more aware of the NMU's environmental impact after using the NMU Eco-Feedback application. Participants became more aware of their own environmental impact and what changes could be made to reduce this impact in their daily activities.

The functionality of the NMU Eco-Feedback application confirmed the design of ecofeedback systems as indicated by Dubois and Pittarello (2018). The colour-coding, symbols and visualisation techniques assisted in finding relevant information regarding the institution's environmental impact as proposed by Frittzpatrick and Smith (2009). The tips assisted participants in becoming more aware of their own environmental impact and of how they could reduce this environmental impact.

The limitations of this exploratory study were the small sample size, using a convenience sample, the scale (questionnaire) containing only eight items and the environmental data not being updated in real-time. Current research involves evaluating the NMU EcoFeedback application using students from different faculties, extending the questionnaire to focus on the factors, environmental awareness knowledge, attitudes and behaviour (Kencanasari et al., 2019), as well as using real-time environmental data. Future research 
includes the development of mobile applications, serious gamification and the use of social media campaigns for use by students to create environmental awareness and influence and promote changes in environmental behaviour.

\section{Notes on Contributors and their Contributions}

\section{Lead author}

Calitz, Andre

Andre Calitz is a professor in the Department of Computing Sciences at the Nelson Mandela University, South Africa. His research interests include environmental awareness and sustainability at Higher Education Institutions.

\section{Co-author}

Cullen, Margaret

Margaret Cullen is a professor at the Business School at the Nelson Mandela University, South Africa. Her research interests include happiness and environmental sustainability entrepreneurship.

\section{Co-author}

Odendaal, Francois

Francois Odendaal completed a BCom Honours degree in the Department of Computing Sciences at the Nelson Mandela University. His research focused on creating environmental awareness amongst students. He is currently a Systems Analyst in the IT industry.

\section{Percentage contribution}

\begin{tabular}{|l|l|c|}
\hline \multirow{3}{*}{ Areas of contribution } & Author & $\begin{array}{c}\text { Percentage } \\
\text { contribution }\end{array}$ \\
\hline \multirow{3}{*}{ Conception or design of the paper, theory or key argument } & Calitz & $60 \%$ \\
\cline { 2 - 3 } & Cullen & $30 \%$ \\
\cline { 2 - 3 } & Odendaal & $10 \%$ \\
\hline \multirow{3}{*}{ Analysis and interpretation } & Calitz & $10 \%$ \\
\cline { 2 - 3 } & Cullen & $10 \%$ \\
\cline { 2 - 3 } & Odendaal & $80 \%$ \\
\hline \multirow{2}{*}{ (a) } & Calitz & $40 \%$ \\
\cline { 2 - 3 } & Cullen & $10 \%$ \\
\cline { 2 - 3 } & Odendaal & $50 \%$ \\
\hline
\end{tabular}




\begin{tabular}{|l|l|c|}
\hline Areas of contribution & Author & $\begin{array}{c}\text { Percentage } \\
\text { contribution }\end{array}$ \\
\hline \multirow{3}{*}{ Drafting the paper } & Calitz & $70 \%$ \\
\cline { 2 - 3 } & Cullen & $20 \%$ \\
\cline { 2 - 3 } & Odendaal & $10 \%$ \\
\hline
\end{tabular}

\section{References}

Akintunde, E.A. (2017). Theories and Concepts for Human Behavior in Environmental Preservation. Journal of Environmental Science and Public Health, 1(2), 120-133. doi: 10.26502/JESPH.012.

Association for the Advancement of Sustainability in Higher Education. (2012). Sustainability Tracking, Assessment \& Rating System. STARS 2.0 Technical Manual. Retrieved May 3, 2019 from https://www.sustainablepurchasing.org/wp-content/ uploads/2013/05/STARS_2.0_technical_manual.pdf

Bandura, A. (1969). Principles of Behavior Modification. New York, NY: Holt, Rinehart \& Winston.

Biswas, A. \& Roy, M. (2016). A study of consumers' willingness to pay for green products. Journal of Advanced Management Science, 4(3), 211-215.

Calitz, A.P. \& Zietsman, J. (2018). An Adapted Framework for Environmental Sustainability Reporting using Mobile Technologies. African Journal of Information Systems, 10(3). https://digitalcommons.kennesaw.edu/ajis/vol10/iss3/2

Castelli, N., Ogonowski, C., Jakobi, T., Stein, M., Stevens, G. \& Wulf, V. (2017). What happened in my home?: An end-user development approach for smart home data visualization. 2017 CHI Conference on Human Factors in Computing Systems, Denver.

Cetin, C. \& Nisanci, S.H. (2010). The effectiveness of the new 9th grade biology curriculum on students' environmental awareness. Asia-Pacific Forum on Science Learning and Teaching, 11(2), 1-25.

Chappin, E.J.L. Bijvoet, X. \& Oei, A. (2017). Teaching sustainability to a broad audience through an entertainment game - The effect of Catan: Oil Springs. Journal of Cleaner Production, 156, 556-568.

Cruz, J.P. \& Tantengco, N.S. (2017). Students' environmental awareness and practices: Basis for development of advocacy program. Indonesian Journal for Educational Studies, 2(1), 43-64.

Darby, S. (2006). The Effectiveness of Feedback on Energy Consumption: A Review for DEFRA of the literature on metering, billing and direct displays. Oxford: University of Oxford, Environmental Change Institute.

Derr, V. (2020). Diverse perspectives on action for positive social and environmental change. Environmental Education Research. doi:10.1080/13504622.2020.1715925. 
Dubois, E. \& Pittarello, F. (2018). Designing Eco-Feedback Systems for a University Campus. Goodtechs '18, 28-30November, 2018, Bologna, Italy. doi:10.1145/3284869.3284889.

Fitzpatrick, G. \& Smith, G. (2009). Technology-enabled feedback on domestic energy consumption: articulating a set of design concerns. Pervasive Computing, 8(1), 37-44.

Fraternali, P., Cellina, F., Herrera Gonzales, S.L. et al. (2019). Visualizing and gamifying consumption data for resource saving: Challenges, lessons learnt and a research agenda for the future. Energy Inform, 2(22). doi:10.1186/s42162-019-0093-z.

Froehlich, J., Findlater, L. \& Landay, J. (2010). The Design of Eco-Feedback Technology. Atlanta, Georgia, USA: ACM.

Gadenne, D.L., Kennedy, J. \& McKeiver, C. (2008). An empirical study of environmental awareness and practices in SMEs. Journal of Business Ethics, 84(1), 45-63.

Gravetter, F.J. \& Wallnau L.B. (2009). Statistics for the Behavioral Sciences (8th ed). Belmont, CA: Wadsworth.

Hamari, J., Koivisto, J. \& Sarsa, H. (2014). Does gamification work? - A literature review of empirical studies on gamification. In Proceedings of the 47th Hawaii International Conference on System Sciences, 6-9 January 2014, Hawaii, USA.

Hamid, S., Ijab, M.T., Sulaiman, H., Anwar, R.M. \& Norman, A.A. (2018). Social media for environmental sustainability awareness in higher education. International Journal of Sustainability in Higher Education, 18(4), 474-491. doi:10.1108/IJSHE-01-2015-0010.

Hartman, C.B., DeMars, C.E., Griscom, H.P. \& Butner, H.M. (2018). Assessment of undergraduate students' environmental stewardship reasoning and knowledge. International Journal of Sustainability in Higher Education, 18(4), 492-502. doi:10.1108/ IJSHE-07-2015-0128.

Hines, J.M., Hungerford, H.R. \& Tomera, A.N. (1987). Analysis and synthesis of research on responsible environmental behavior: A meta-analysis. Journal of Environmental Education, 18, 1-8.

Hough, J., Thompson, A, Strickland, A. \& Gamble, J. (2011). Crafting and Executing Strategy: Creating sustainable high performance in South Africa - Text, readings and cases (2nd ed). Berkshire: McGraw-Hill.

Jakobi, T, \& Schwartz, T. (2012). Putting the user in charge: End user development for eco-feedback technologies. Sustainable Internet and ICT for Sustainability (SustainIT), $1-4$.

Jain, R. K., Taylor, J.E. \& Peschiera, G. (2012). Assessing eco-feedback interface usage and design to drive energy efficiency in buildings. Energy and Buildings, 48, 8-17. doi:10.1016/j.enbuild.2011.12.033.

Johnson, D., Horton, E., Mulcahy, R. \& Foth, M. (2017). Gamification and serious games within the domain of domestic energy consumption: A systematic review. Renewable and Sustainable Energy Reviews, 73, 249-264. 
Jorgenson, S.N., Stephens, J.C. \& White, B. (2019). Environmental education in transition: A critical review of recent research on climate change and energy education. Journal of Environmental Education, 50(3), 160-171. doi:10.1080/00958964.2019.1604 478.

Karlin, B., Zinger, J.F. \& Ford, R. (2015). The effects of feedback on energy conservation: A meta-analysis. Psychological Bulletin, 141(6), 205-227.

Kaur, B. (2019). A study on environmental awareness among college students. International Journal of Scientific and Research Publications, 9(11), 425-427.

Kencanasari, R.A.V., Surahman, U. \& Permana, A.S. (2019). The instrumental framework to measuring environmental awareness. Innovation of Vocational Technology Education, XV (2), 101-109. doi:10.17509/invotec.v15i2.19638.

Klein-Banai, C. \& Theis, T.L. (2013). Quantitative analysis of factors affecting greenhouse gas emissions at institutions of higher education. Journal of Clean Production, 48, 29-38.

Kollmuss, A. \& Agyeman, J. (2002). Mind the gap: Why do people act environmentally and what are the barriers to pro-environmental behaviour? Environmental Education Research, 8, 239-260.

Madani, K., Pierce, T.W. \& Mirchi, A. (2017). Serious games on environmental management. Sustainable Cities and Society, 29, 1-11.

Monroe, M.C., Plate, R.R., Oxarart, A., Bowers, A. \& Chaves, W.A. (2019). Identifying effective climate change education strategies: a systematic review of the research. Environmental Education Research, 25(6), 791-812. doi:10.1080/13504622.2017.1360 842.

Olsen, C.S. (2014). Visualization of energy consumption: Motivating for a sustainable behaviour through social media. Proceedings of International Conference on Collaboration Technologies and Systems, 641-646.

Prochaska, J., Johnson, S. \& Lee, P. (1998). The transtheoretical model of behavior change. In S. Schumaker, E. Schron, J. Ockene \& W. McBee (Eds), The Handbook of Health Behavior Change (2nd ed). New York, NY: Springer.

Roy, P. (2016). A comparative study on environmental awareness between primary and secondary school teachers. International Journal of Research in Economics and Social Sciences, 6(12), 255-259.

Salkind, N.J. (2010). Encyclopedia of Research Design. Thousand Oaks, CA: Sage. doi.org/10.4135/9781412961288.

Spagnolli, N., Corradi, L., Gamberini, E., Hoggan, G., Jacucci, C., Katzeff, L., Broms, L. \& Jonsson, L. (2011). Eco-feedback on the go: Motivating energy awareness. Computer, 44(5), 38-45.

Piccolo, L.S.G., Scharl, A. \& Baranauskas, C. (2012). Design of Eco-Feedback Technology to Motivate Sustainable Behavior: Cultural Aspects in a Brazilian Context. Proceedings of 2012 International Conference on Information Resources Management. Retrieved from http://aisel.aisnet.org/confirm2012/34/ 
Shove, E., Pantzar, M. \& Watson, M. (2012). The Dynamics of Social Practice: Everyday life and how it changes. London: Sage.

Souza, G., Mesquita, R., Lima, P., \& Guerra, E. (2019). Save the Ocean: A Game for Environmental Awareness. SBGames 2019 Conference, 28-31 October, Rio de Janeiro, Brazil.

Sulaiman, N., Chan, S.W. \& Ong, Y.S. (2019). Factors influencing recycling intention among university students. International Journal of Innovative Technology and Exploring Engineering, 8(8S), 336-340.

Thondhlana, G. \& Hlatshwayo, T.N. (2018). Pro-environmental behaviour in student residences at Rhodes University, South Africa. Sustainability, 10, 1-19. doi:10.3390/ su10082746.

Van Houwelingen, J.H. \& Van Raaij, W.F. (1989). The effect of goal-setting and daily electronic feedback on in home energy use. Journal of Consumer Research, 16 (1), 98105. doi:10.1086/209197.

Vine, D., Buys, L. \& Morris, P. (2013). The effectiveness of energy feedback for conservation and peak demand: A literature review. Open Journal of Energy Efficiency, 2(1). doi:10.4236/ojee.2013.21002.

Walton, S.V. \& Galea, C.E. (2005). Some considerations for applying business sustainability practices to campus environmental challenges. International Journal of Sustainability in Higher Education, 6(2), 147-160.

Yendapally, D. \& Yazdansepas, D. (2020). Designing an interactive eco-feedback environment. In: C. Stephanidis \& M. Antona (eds) HCI International 2020 Posters. Communications in Computer and Information Science, vol 1224. Springer. doi: 10.1007/978-3-030-50726-8_40.

Zyadin, A. (2015). Prospects for renewable energy education (REE) in elevating youth energy and environmental awareness in Jordan. Unpublished thesis, Finnish Society of Forest Science, Helsinki. 